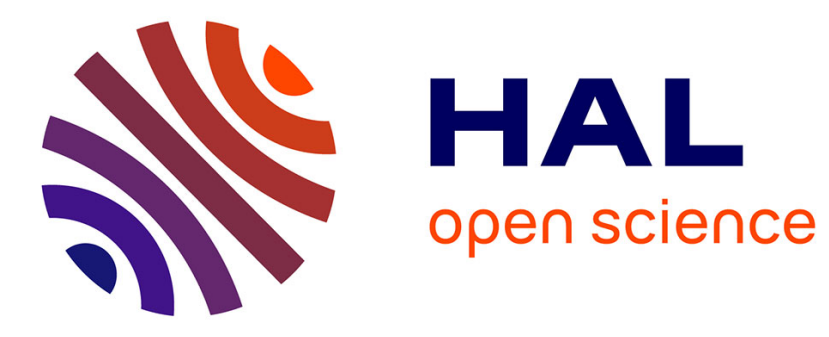

\title{
Affordance Lost, Affordance Regained, and Affordance Surrendered
}

\author{
Divya Sharma, Biswatosh Saha, Uttam K. Sarkar
}

\section{To cite this version:}

Divya Sharma, Biswatosh Saha, Uttam K. Sarkar. Affordance Lost, Affordance Regained, and Affordance Surrendered. Working Conference on Information Systems and Organizations (ISO), Dec 2016, Dublin, Ireland. pp.73-89, 10.1007/978-3-319-49733-4_5 . hal-01619193

\section{HAL Id: hal-01619193 \\ https://hal.inria.fr/hal-01619193}

Submitted on 19 Oct 2017

HAL is a multi-disciplinary open access archive for the deposit and dissemination of scientific research documents, whether they are published or not. The documents may come from teaching and research institutions in France or abroad, or from public or private research centers.
L'archive ouverte pluridisciplinaire HAL, est destinée au dépôt et à la diffusion de documents scientifiques de niveau recherche, publiés ou non, émanant des établissements d'enseignement et de recherche français ou étrangers, des laboratoires publics ou privés.

\section{(c)(1)}

Distributed under a Creative Commons Attribution| 4.0 International License 


\title{
Affordance Lost, Affordance Regained, and Affordance Surrendered

\author{
The Becoming of Reachability on Social Media Platforms
}

\author{
Divya Sharma, Biswatosh Saha, Uttam K. Sarkar \\ Indian Institute of Management Calcutta, Kolkata, India \\ \{divyas12,biswatosh, uttam\} @imcal.ac.in
}

\begin{abstract}
Informed by the ontology of becoming, this study explores technological affordances in the context of use of social media technologies where multiple human and material agents interact without necessarily being co-present. In such scenarios, tracing the relational configuration of social and material agents becomes a challenge. So far, extant literature based on the ontology of becoming has only considered the actualization of affordances in the proximal co-presence of other people and objects. Extending this understanding of affordances by using actor-network theory (ANT) as a methodological and conceptual device, this research traces translations of the "distant" in the form of inscriptions that can travel across space and time. This study points towards the utility of using ANT, over other interpretive methods, as a tool to study complex technological phenomena. It shows that affordances are collective, ongoing accomplishments of diverse actors, some co-present physically and others, though distant, co-present through translated representations.
\end{abstract}

Keywords: affordance $\cdot$ ontology of becoming $\cdot$ actor-network theory (ANT) $\cdot$ copresence at a distance $\cdot$ social media.

\section{Introduction}

Interest in the relationship between the social and the material in the context of technologically enabled organizing and social life has intensified over the past few years. Hence, there has been a proliferation of studies that augment, complement, as well as question the received views [1]. Our study attempts to carry forward this thread of enquiry by a commitment to an ontology of becoming [2]. We extend the notion of affordances actualized in the co-presence of multiple human and material agents [3] to scenarios where this co-presence may not be synonymous with physical proximity [4]. 
While, social media technologies offer features and functionalities which can be appropriately chosen by managers for the benefit of their organizations [5], these features and functionalities are known to, in turn, frame the activities of these managers [6]. As a result of this intertwining, researchers have called for a relook the artificial separation of the social from the material [7]. The ecological concept of affordance [8] that provides for a relational understanding between technology and humans has been lauded as promising to understand the organizational use of information technology [9].

A significant body of research on technological affordances assumes an a priori substantial nature of the social and the material, such that the social agent is the source of action. According to this notion, affordances are actualized when human agency interacts with the materiality of a technology, and in so doing invokes the material agency of that technology $[10,11]$. Based on this conceptualization, scholars have tried to understand the actualization of technological affordances in different scenarios, including social media (for example, $[12,13]$ ). This nascent body of work on social media affordances, however, suggests a static character of affordance, where a particular technology affords doing something [14]. However, the actualization of affordances on social media involves "dynamic interactions" among heterogeneous entities, such as human agents in their various capacities, as individual users and as business users, and material agents in the form of technological functions and algorithms.

Recognizing that action and interaction are inherent to affordances [15], another body of work has developed based on the ontology of becoming [2] that conceptualizes affordances as ongoing accomplishments [3]. This literature has explored the actualization of affordances when multiple human and material agents are proximally co-present, resulting in "cascades of affordances". Here a contraption of social and material agents actualizes the affordance [16] through sequential or iterative enactments. Accordingly, "affordances" of technological objects cannot be easily separated from the arrangements that are performatively realized in practice [3]. These arrangements are nothing but processes of ongoing becoming called assemblages [2]. Assemblages are not complete "things" possessing a priori primary qualities. Rather, their qualities are emergent accomplishments of ongoing flows and movements.

In this study, we present our findings with regard to one particular affordance in the context of use of Facebook, an extra-organizational social media platform, by a firm for the purpose of branding and marketing communication. Informed by the ontology of becoming, we set out to trace the ontological history of an affordance [2]. However, we soon realized that the various agents that performatively enacted the affordance were not proximally co-present [16]. It, therefore, became a challenge to trace the relational constitution of the affordance. For example, when Facebook affords association between two individual users, those users are not copresent in the same space or time. However, they are co-present, while at a distance [4], in the form of their representations on the social media platform, such as their profile information and the content that they created on the platform. In order to 
deal with co-presence while at a distance, we resorted to actor-network theory (ANT), which, through its methodological and theoretical premises, provided us the language and the means to trace the flow of becoming of a heterogeneous assemblage, enabled to afford a particular action. We were, hence, able to "follow the actors" [17] on scene, and trace mobile agents that represented their intra-actions. In so doing, we illustrate the utility of ANT, over other interpretive methods, in understanding affordances as a collective accomplishment of diverse actors, some co-present physically and others co-present while at a distance.

This paper is organized according to the following scheme. We first present the theoretical background, followed by the research context. Thereafter, we elucidate the methodology and present our findings. Subsequently, we provide a detailed discussion and conclusion.

\section{Theoretical Background}

\subsection{Co-presence and the Becoming of Affordances}

The theory of affordance, rooted in the area of Ecological Psychology, posits affordances as complementarities between the animal and the environment [8]. By pertaining to both the environment and the observer, affordances go beyond the objective by expressing environmental attributes relative to humans, and go beyond the subject by describing meaning relative to the objective world [15]. Due to the ability of the concept of affordance to overcome the objective-subjective divide, it has been proposed that this concept might assist in better understanding organizational use of information technology (IT) [9].

Literature on technological affordance in the domain of Information Systems (IS) describes affordance as the possibility for goal-oriented action made available to a user by the technology [18]. Affordances are unlike properties of the technical artifact, since affordances are relational in nature, pertaining both to the people who use the technology, as well as the materiality of the technology itself [11]. For example, the affordance of visibility [12], that is making information about oneself visible to other users on Facebook, is actualized through the invocation of the material features of the Facebook interface by a Facebook user. Here, visibility is an affordance, and not a property of Facebook that exists independent of the user.

There seem to have developed two distinct conceptualizations of the notion of affordance, especially with respect to the ontological status of an affordance. The first conceptualization assumes that affordances are realized in a gradual imbrication of distinct social agencies with material agencies, which further leads to their overlap and subsequent interdependent function [13], [19, 20]. However, the artificial separation between the social and the material seems to have been reinforced by this body of literature. Furthermore, this literature espouses a static notion of affordance where a technological object affords certain action [14]. The artificial divide and the static notion of affordance are especially problematic for the study 
of social media contexts where the social and the material interact and are fundamentally co-constitutive [21]. Departing from the notion of affordances based on a "distinct irreducible character" of agents, an alternative conceptualization bases the notion of affordance on the ontology of becoming [2, 3], [14]. This requires a shift from the understanding that a being offers affordances, to an alternate understanding where becoming enabled to afford a particular action is an ongoing accomplishment of a heterogeneous assemblage [2]. This assemblage is a framing of ontological openness. This implies that the assemblage does not possess any a priori primary and secondary qualities, such that any change only happens in the secondary properties. Rather, there exists no boundary between primary and secondary qualities, and all changes affect the primary qualities of the assemblage. Thus, all qualities emerge in ongoing flows and movements. Hence, according to the ontology of becoming, affordances are "dynamic" [14], since they do not pre-exist, but emerge only in action.

Furthermore, the former conceptualization assumes a dyadic notion of affordance where an affordance is actualized in the relationship between an individual user and a technological artifact. Again, such an understanding restricts the explanation of affordances actualized in the presence of multiple people and objects [3]. For example, Facebook also affords a user to associate [12] with another user on the network, where the affordance to associate is not actualized between an individual user and the technological platform, but between multiple users. Here too, the latter conceptualization of affordance allows for a conceptualization involving copresent people and objects that collectively accomplish an affordance [3]. Michael [16] proposes the concept of "cascades of affordances" to understand the actualization of affordances in the co-presence of multiple actors. For example, the affordance of walkability on snow is explained as: socks affording easier wearing of boots which afford attachment of crampons which afford climbing snow-covered slopes [16]. However, in the example of the affordance to associate on social network, the two users are not co-present. Hence, this scenario is not akin to a "cascade of affordances" where a contraption of proximally situated social and material agents actualizes the affordance (cf. [3]). Instead, we observe that spatially and temporally distanced users collectively intra-act with the materiality of Facebook to ontologically constitute themselves as "friends" on Facebook.

Complex technological environments, such as social media, often lack co-presence of their users, and their material feature and algorithms. For example, Twitter's Trends algorithm identifies topics of interest for a user by accounting for the actions of thousands of users who lack co-presence with this particular user. With the proliferation of such phenomena, exploring the actualization of affordances where copresence is not a necessary condition can help in making better sense of organizing.

\subsection{Following the Absently Present Actors}

It is clear that tracing intra-actions among heterogeneous agents that might not be co-present is crucial to understanding the becoming of affordances on social media. 
Social media may be described as a virtual space-time where people engage without "bodily co-presence" [4]. However, for us the challenge lay in accounting for the invisible but present [22] entities inhabiting the scene and the consequences thereof. On social media, it may be observed that the absent become present in the form of "contrivances" that allow translation without corruption [23]. Here, translation implies the possibility that one thing may stand for another [24]. For example, users' profile pages stand for individual users, users' posts stand for their views, users' "likes" on other users' posts stand for their interests, and so on. Taking a cue from the existence of such translations, we resorted to ANT that suggests "following the actors" as they construct a network of point-to-point connections that are made of traces left behind by some moving agent [17]. These moving agents are, what Latour [23] calls, inscriptions that render the traces mobile and immutable. However, inscriptions also "bracket away" the relationships between actors, foregrounding some details and suppressing many others relating to events and contingencies involved in their production [25]. On social media, the physically absent gains presence [26] through the translation of inscriptions, such that distant exchanges seem co-present. For example, when a user "comments" on a post by another user on Facebook, even though the local contingencies contributing to the user's comment are suppressed, this comment gets inscribed into the materiality of the interface, travelling across space and time, to constitute a conversation between the two users co-present while at a distance [4]. In this way, the inscribed "comment" is delegated the action of the user [23], such that the user becomes absently present through the comment [22]. Furthermore, these inscriptions can be superimposed, reshuffled, recombined, and summarized [23], thereby becoming translations that can travel across space and time, mediating the relationship between heterogeneous entities, and in so doing relationally defining them [24]. Going back to the previous example, the materially inscribed conversation relationally defines the two users as partners in the same conversation. Further, multiple such conversations emanating in the form of "comments" on the same post can be summarized to indicate that the post relates to a topic of interest to a wider Facebook audience, such that the users who commented on the post get relationally defined as sharing that interest.

\section{Research Context}

In this paper we present the findings from our fieldwork at a firm, henceforth referred to as OMEGA, founded in mid-2012 as an online retail store dealing in accessory solutions across different lifestyle segments, and catering to Indian customers. Owing to the rising adoption of smartphones in India, ${ }^{1}$ the company discontinued sale of all other accessories and solely entered the category of smartphone cases in January 2014. The founders of OMEGA positioned designer

\footnotetext{
${ }^{1}$ See [40].
} 
and customizable cases as a means of improving the "look" of the smartphone. They aspired to make such cases a medium of personal expression, not merely a means of protecting the fragile body and screen of the smartphone. The company tied up with renowned designers from across the world through exclusive contracts to offer around 2,000 designs for cases across 105 smartphone models. As of mid-2015, the company had sold more than 120,000 smartphone cases.

OMEGA was solely dependent on online channels for promoting its brand, and social media platforms were considered most potent in allowing direct connection with existing as well as potential customers. The firm is active on each of Facebook, Twitter, Instagram, and Pinterest. During our fieldwork, the company reported spending approximately $70 \%$ of its total budget on social media marketing, with Facebook accounting for close to $90 \%$ of this spending. OMEGA had also set up a brand Page on Facebook, a facility that enabled it to connect and interact with interested Facebook users without having to pay Facebook.

At the time we began our research, the company extensively used its brand Page to interact with Facebook users. But, our initial interviews with the employees of the company revealed a rising sense of wariness towards the benefit of posting content on its Page, due to changes in Facebook's algorithms that governed which users saw its posts. We felt that this flux in situation was an interesting starting point to enquire how an extra-organizational technology could enable and constrain businesses. Our fieldwork revealed that the wariness reported initially was not longlasting, with distinct phases of ebb and flow in OMEGA's confidence with respect to using Facebook for branding and marketing communication. Our study traces these variations, and illustrates that this undulation was an outcome of not just the changes in Facebook's algorithms, but also the intentions and continuous doings of OMEGA's marketers, Facebook's managers, and Facebook users.

\section{Methodology}

Before delving into the field, a preliminary background research was conducted in order to gain insights into the practices and concerns of firms that primarily use ecommerce as their mode of transactions. Approximately twenty informal interactions conducted in-person and telephonically helped us realize that, while the firms' accomplishments ostensibly appeared to be results of organizational practices, they were in fact the result of actions performed by a gamut of heterogeneous human and non-human agents. The recurrence of non-human agents in our context motivated us to choose actor-network theory as a method for data collection and subsequent data analysis. Being both a theory and a methodological approach [17], ANT provided us with theoretical concepts, as well as suggestions on carrying out empirical work [27].

\subsection{Method}


ANT accepts that both human and non-human actors can be the origin of actions [28], and agency is a privilege of not only humans, but, also non-humans, inanimate objects and artifacts $[29,30]$. These tenets were especially useful for us as we delved into a field replete with human and material agents. Drawing on ANT, we followed the various actors through their work, examining their diverse positions, controversies and outcomes [31]. Interviews gave us the wherewithal to travel across space and time [32] to collect accounts on current and past intra-actions of the organizational human actors with technological artifacts. As we had expected, from the very beginning we encountered a heterogeneous cache of non-human agents including websites, blogs, software, algorithms, and artifacts. In the case of social media, prior research has found it challenging to empirically investigate software and algorithmic agents due to non-disclosure of details about them [33]. Employing ANT, we were able to follow these new actors on the scene by exploring websites, online user manuals and help pages, publicly available online articles, and developers' documentation. The prior training and experience of the researchers in technology assisted in making sense of the collected artifacts as we delved deeper into the technical aspects of the technical agents. In following the actors, a network of relations started emerging between these heterogeneous elements and we started tracing the intra-actions that represented the work being performed in this network [34].

\subsection{Data}

This study is based on data collected from April 2015 to April 2016. Since the focal firm, OMEGA, is located in a different geographical region from the university where the authors are stationed, one of the authors made three trips, of three weeks, five weeks, and four weeks duration respectively, for the purpose of data collection to the region where the firm is located. Interviews, informal discussions, and observation of the day-to-day practices of employees of the company were used for data collection on-site. In addition to the two co-founders and personnel responsible for marketing, operations, and technology functions, the author also interacted with various other employees and visited the site on multiple occasions to observe and understand the workings of various teams. The author revealed her identity as a researcher and the purpose of her research to each member of the firm with whom she interacted, reassuring that anonymity will be maintained and no comments will be attributed to them in any subsequent discussions or reporting [35]. Most interviews were conducted either on-site or telephonically in a semi-structured fashion. The average duration of an interview was approximately 90 minutes. After seeking due permission from the interviewees, all but three interviews were digitally recorded. Details of the interviews that were conducted are presented in Table 1. Notes were taken for the interviews that were not recorded. The author transcribed most interviews verbatim. A record of multiple interactions over e-mail and instant messenger, mainly dealing with clarification of doubts and gathering statistical information from the informants, also formed part of the data corpus. Furthermore, the author maintained a research diary to make note of her informal interactions with the employees and keep records of her observations on-site. 
Table 1. Details of interviews at OMEGA

\begin{tabular}{llll}
\hline Informant & $\begin{array}{l}\text { Number of inter- } \\
\text { views }\end{array}$ & $\begin{array}{l}\text { Interview dura- } \\
\text { tion (hrs) }\end{array}$ & Recorded \\
\hline $\begin{array}{l}\text { Co-founder \& Chief Execu- } \\
\text { tive Officer (CEO) }\end{array}$ & 3 & 4.5 & Yes \\
$\begin{array}{l}\text { Co-founder \& Chief Operat- } \\
\text { ing Officer (COO) }\end{array}$ & 1 & & (1 telephonic) \\
$\begin{array}{l}\text { Manager } \\
\text { (Marketing \& Strategy) }\end{array}$ & 3 & 1 & No not recorded) \\
Category Manager & $(2$ telephonic) & 5 & Yes \\
Tech Lead & 1 & 2.5 & (1 telephonic not recorded) \\
\hline
\end{tabular}

Interviews with OMEGA's personnel revealed that they often referred to a plethora of official blogs, articles, and online help pages to better utilize the possibilities offered by social media. In the spirit of ANT we followed these traces to access publicly available digital artifacts over the Internet. While providing an exhaustive list of online resources used is not possible due to space constraints, an indicative list of these artifacts is presented in Table 2.

Table 2. Indicative list of web resources

\begin{tabular}{lll}
\hline Webpage/Blog & URL & Content Description \\
\hline $\begin{array}{l}\text { Facebook } \\
\text { for Business }\end{array}$ & www.facebook.com/business/ & $\begin{array}{l}\text { Latest news, tips and best practices } \\
\text { for businesses who use Facebook }\end{array}$ \\
$\begin{array}{l}\text { Facebook } \\
\text { Newsroom }\end{array}$ & newsroom.fb.com/ \\
$\begin{array}{l}\text { Facebook for } \\
\text { Information and news about Face- } \\
\text { book, its products, its investors, etc. }\end{array}$ \\
$\begin{array}{l}\text { Facebook } \\
\text { Help Center }\end{array}$ & developers.facebook.com/blog & $\begin{array}{l}\text { Product documentation, tools and sup- } \\
\text { port for Facebook's APIs }\end{array}$ \\
$\begin{array}{l}\text { Jon Loomer } \\
\text { for Advanced }\end{array}$ & www.facebook.com/help/ & $\begin{array}{l}\text { Support for individual and commer- } \\
\text { cial Facebook users }\end{array}$ \\
$\begin{array}{l}\text { Facebook Marketers } \\
\text { TechCrunch }\end{array}$ & www.jonloomer.com/ & Marketing tactics for Facebook \\
\hline
\end{tabular}

\subsection{Analysis}

OMEGA used social media for varied purposes including advertising, branding, and marketing communication. In this paper we restrict our findings to those pertaining to branding and marketing communication. We started off with the preconception that social media as a technology would afford, that is, allow and forbid, certain actions by those who act on it [36]. However, in following one actor after another and tracing their interrelationships, we understood that most of the actors that we 
were following, along with their practices, constituted what we had black boxed [32] as "social media". Opening this black box to unravel nuances about organizational practices helped us in foregrounding the multiple intra-actions between entities, such as individual Facebook users, personnel at OMEGA, OMEGA's competitors, managers at Facebook Inc., and algorithms, which were essential to the becoming of the socio-technical assemblage being traced. We realized that many of the entities of interest to us were physically absent from the scene, but were notionally present. By invoking the conceptual categories of absent presence [22] and translation [24], we were able to trace the ontological history [2] of one particular affordance that we tracked.

\section{$5 \quad$ Findings}

\subsection{Reachability: The Becoming of an Affordance}

The niche nature of OMEGA's product required pushing information to potentially interested audiences to spread awareness about its offerings. Even though display networks allowed marketers at OMEGA to place ads on websites where potentially interested audiences were likely to visit, these ads appeared as nothing but a distraction to the visitors. As an alternative, the marketers decided to utilize social media's affordance to reach out to potentially interested audiences, through branding and marketing content, in a manner that did not strike as disturbing.

In social media it is different. Here you reach out to a user who is not expecting your ad, but you [can] show things very nicely to him. So he gets to know about your service.

OMEGA's Facebook brand Page proved to be an especially useful medium to organically reach out to potentially interested Facebook users. Organically reaching out implies that content posted on OMEGA's Page, unlike ads, can be made to appear in the News Feed of Facebook users without paying Facebook. News Feed is described on the Facebook Help Center ${ }^{2}$ as follows:

News Feed is the constantly updating list of stories in the middle of your home page. News Feed includes status updates, photos, videos, links, app activity and likes from people, Pages and groups that you follow on Facebook.

Facebook users can follow a brand Page, by clicking on a "Like" button provided by Facebook's materiality on the Page, thereby explicitly showing interest in being served content posted on the Page in their News Feeds. As of mid-2015, OMEGA's Page had close to 400,000 followers. This implied that not only could OMEGA

${ }^{2}$ See [41]. 
reach out to this large population of Facebook users organically, but also non-obtrusively through a native display of visual content using features provided by the interface. As a result, OMEGA's Page posts usually consisted of images depicting its products and services, which were then served in the News Feed of OMEGA's followers.

[Facebook is] a place where customers and others can interact with us, plus they get to know about our services - when we post ... [I]t is a very visually strong medium, where if photos are shared, they show big in size and are displayed natively [in the News Feed], they are part of the experience ... The Facebook inventory is very strong visually, so it is best for us.

In this way, marketers at OMEGA constituted themselves as business users of the social network by invoking Facebook's material agency to set up a Facebook Page. Similarly, when individual Facebook users invoked Facebook's material agency to "Like" OMEGA's Page, they were able to re-constitute themselves as OMEGA's Page followers, in addition to being Facebook users. In this relational re-constitution of Facebook users into OMEGA's followers, these followers got mobilized to be absently present [22] as allies of OMEGA, to whom content created by OMEGA's marketers may be pushed by Facebook's material agency in future. The re-constitution of OMEGA's marketers and its Page followers is a relational effect [24] of the interactions that these actors have with Facebook's materiality. The establishment of these point-to-point connections allows Facebook's algorithms to send mobile agents [17] in the form of Facebook posts created by OMEGA's marketers to its thousands of absently present followers. Even though these circulating Page posts "bracket away" all the local contingencies of their production [25], they allow OMEGA's marketers and its followers to become co-present while at a distance [4]. We define OMEGA's ability to reach potentially interested audiences with Page posts as the affordance of reachability. This affordance is not actualized by the physical "co-presence" [16] of other people and other objects [cf. 3], but by the translation of other actors in the form of inscription across space and time [23], that then become co-present through these representations.

Hence, reachability is actualized not in the interaction between OMEGA's marketers and Facebook's materiality [15], but is accomplished in the multiple intraactions among heterogeneous actors constituting an assemblage. This assemblage does not possess a pre-existing reachability, but in the multiple intra-actions, becomes performatively enabled to "reach". For example, Facebook users transform into Page followers by intra-acting with the material feature provided by Facebook; OMEGA's marketers utilize Facebook's materiality to post visual content to their Page; and this content gets pushed to the News Feed of OMEGA's Page followers. Here, agency exercised does not belong to a single actor or a set of actors, but intraactions among heterogeneous actors, their flows and movements, collectively contribute to the becoming of an assemblage enabled to reach potentially interested audiences [2]. 


\subsection{Affordance Lost: Fragility of Assemblage}

The initial experience of OMEGA's marketers was that posts made on its Page reached the News Feed of most of its followers. However, over time the number of people that OMEGA could organically reach started declining. The marketers attributed this to a change in the way that Facebook served the News Feed.

On Facebook, the reach has been restricted. If I have 3 hundred thousand followers and I make a post on the Page, it will reach only 2,000-3,000 people ... It's based on relevance - who will be the people interested in reading your post.

A marketer at OMEGA informed us that in an article in "Facebook for business" the lead of the Ads Product Marketing team of Facebook ${ }^{3}$ had explained two reasons for declining organic reach. When we accessed the article dated 5 June 2014, we found that the first reason related to increasing competition for space in users' News Feeds, and the second was regarding the filtering of content shown to users by the News Feed algorithm:

The first reason involves a simple fact: More and more content is being created and shared every day ... On average, there are 1,500 stories that could appear in a person's News Feed each time they log onto Facebook ... In addition to the growth in content, people are also liking more Pages ... With each new Page like, competition in News Feed increases even further ... The second reason involves how News Feed works. Rather than showing people all possible content, News Feed is designed to show each person on Facebook the content that's most relevant to them. Of the 1,500+ stories a person might see whenever they $\log$ onto Facebook, News Feed displays approximately 300. To choose which stories to show, News Feed ranks each possible story (from more to less important) by looking at thousands of factors relative to each person.

The News Feed algorithm constitutes the materiality [7] of Facebook and is coded to decide which content to serve to whom [37]. As is evident in the above quote, the algorithm is designed to calculate the relevance of each post created by a business/individual user, for every other user. By performing these calculations and serving content accordingly, the algorithm re-configures the connections that relationally define individual users and marketers. This can be illustrated through the long lag between the change in Facebook's algorithm (implemented some time in 2013) ${ }^{4}$ and OMEGA experiencing a decline in reach (in early to mid-2015). The competition for space in a Page follower's News Feeds, mutually defines the follower in relation to OMEGA. Importantly, it also defines OMEGA in relation to its competitors, who are absently present [22] in the form of their circulating posts and

\footnotetext{
${ }^{3}$ Source: [42].

${ }^{4}$ See $[43]$.
} 
ads. As competition intensified over time, the filtering of posts based on relevance by the News Feed algorithm led to many of OMEGA's followers not receiving its posts. Hence, OMEGA ceased to be co-present, even at a distance [4], for these followers. The intra-actions among competing advertisers, and between advertisers and the News Feed algorithm through mediating advertisers' posts, collectively reconstituted the flow of becoming of the heterogeneous assemblage that did not inherently lack the affordance of reachability, but in the establishment of a relational configuration, became enabled to "constrain reach". Hence, OMEGA's ability to reach out to interested Facebook users through unpaid Page posts got restricted, explicating the essential fragility of the heterogeneous assemblage [3]. In this way, the affordance of reachability is lost, as OMEGA fails to be co-present with its followers.

\subsection{Affordance Regained: Collective Reconstitution of Assemblage}

The prior experience of OMEGA's marketers on Facebook revealed that Page posts, to which interested Facebook users could relate to, were shared by these users more often than other posts with mundane content. Sharing of content was a feature made available by Facebook that enabled a user to share specific content with his or her friends on Facebook. As a result, OMEGA's management decided to leverage the artwork that they received for printing on cases for smartphones from the renowned designers with whom OMEGA had exclusive contracts. Furthermore, OMEGA tied up with bloggers specializing in photography to post content for them.

We don't use photoshopped images now. We have tied up with 10 photo bloggers and made them post for us. Recently we [also] decided that, since we are a design focused company, so we should use our artwork. So we allow that to be shared on Facebook, and they get so many shares.

Photographs and artwork, therefore, became mobile agents that could pass through the connections [17] between designers/photo-bloggers and OMEGA, and between OMEGA and its followers on Facebook. By sharing such content with other Facebook users, the followers of OMEGA enabled the co-presence of OMEGA while at a distance [4] with these other users as well. Similarly, when a Facebook user responded to a Page post by OMEGA by clicking on the "like" button next to it, the post might get served to other Facebook users in the network of this user. As explained earlier, the News Feed algorithm served this post to these other users based on its relevance to them and competition in their News Feeds. All this work being performed in the actor-network led to redefinition of OMEGA in relation to Facebook users who were not its followers, thereby extending its reach beyond its follower base. 
A post will go first of all to the News Feed of the people who Like our Page, but, it will go [only] to around $2 \%$ of those people, because Facebook has limited the reach. Then supposing someone likes it, then it will be shown to his friends. These will be [either] those who have maybe liked the brand Page, or may not have liked it. So, that ways the reach keeps increasing. The probability [of the post reaching News Feed] is more for people who engage with the posts of this person. It's based on relevance ... those will be the people who keep interacting with [this individual] on [her] Facebook posts ... We try to have posts that people can like and share.

By taking advantage of the intra-actions between Facebook's materiality and Facebook users when they respond to posts, OMEGA's marketers were able to delegate some of their work to their followers [38]; that of putting agents, in the form of posts, into circulation through connections in the network. The intra-actions between OMEGA and its followers, and OMEGA's followers and their friends, collectively reconstituted the heterogeneous assemblage. Becoming enabled to "reach" was an ongoing accomplishment [2] for this assemblage through the intra-actions between OMEGA and its followers, and among the followers and their friends. Hence, the relational configuration that affords reachability was regained.

\subsection{Surrendered Affordance: Assemblage Becoming Non-existent}

The competition for space in the News Feed of Facebook users has been increasing, and most firms that maintain brand Pages on Facebook are experiencing a decline in the organic reach of their posts. This declining reach has become a hot topic of debate among various experts ${ }^{5}$ who are trying to understand the impact of this decline on businesses. A marketer at OMEGA quoted one such report ${ }^{6}$ by a team of social experts, social@Oglivy, to explain that despite all their efforts, the organic reach for OMEGA's posts has been declining further:

Facebook's organic reach is constantly decreasing. It [is said to have] fallen from $16 \%$ in 2012 to only $2 \%$ in 2014 . Some say it is lesser than $1 \%$. This constant decrease has also popularized a term called "Facebook Zero" where brands are already getting prepared for the day when the organic reach falls to zero. On an average our last 5 organic posts' reach has been $0.31 \%$.

Owing to the sharp decline in reach, marketers at OMEGA started paying Facebook for having Page content exposed to more users than was otherwise served by the News Feed algorithm. This feature, called boosting, is available to Page owners, and is explained by Facebook ${ }^{7}$ as follows:

$\begin{array}{ll}5 & \text { See, for example, }[43,44] \\ 6 & \text { See }[43] . \\ 7 & \text { See }[45]\end{array}$


Boosting posts is an effective and inexpensive way to get more exposure for your content. It's a simple and easy process - posts are boosted right from your Facebook Page - and you can boost a post for any amount you want ... It's a great way to get more people to see your posts, promote special events, offers and news, and to reach new audiences through targeting.

While marketers at OMEGA circulated payments to Facebook as another element to ensure its co-presence while at a distance with individual Facebook users, paying for reach was counter to the logic of unpaid organic reach. Over time, marketers at OMEGA saw little value in posting content on its Page. Our data revealed that the number of Page posts made by marketers at OMEGA almost halved by the end of 2015 in comparison to the beginning of the year. Figure 1 depicts the quarterwise trend of the number of Page posts by OMEGA on Facebook.

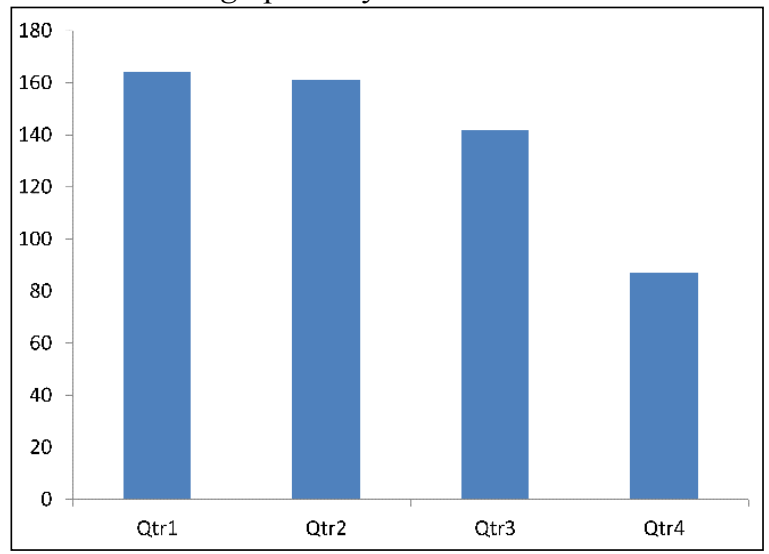

Fig. 1. Quarter-wise number of Page posts by OMEGA in 2015

As marketers at OMEGA withdrew from Facebook, they started looking for other mediums where they could organically reach out to potentially interested customers. In other words, marketers at OMEGA started exploring other means to be co-present with interested audiences on the Internet.

Most posts with more than 100 engagements are boosted. The organic reach on Facebook has almost reached zero. The posts are not reaching people, so we have to boost [most of the posts]. That is why we are shifting to Instagram now. That is doing very well for us. We are also using Pinterest ... The total number of posts on Facebook are declining now, because we are not investing much on Facebook. The returns here are quite less. We are trying to shift to other mediums. In fact nowadays, I am trying to find ways of getting engagement on different channels without any payment. 
In this way, OMEGA stopped circulating moving agents through the connections that linked it to its followers on Facebook, the affordance of reachability on Facebook was surrendered, and the heterogeneous assemblage dissolved into non-existence. In other words, with the decline in intra-actions among the actors constituting the heterogeneous assemblage, the becoming of the affordance of reachability was stalled. OMEGA's marketers started looking for new allies on other social media platforms, establishing new relationships, and attempting co-presence while at a distance outside this heterogeneous assemblage.

\section{Discussion and Conclusion}

In this research we adopt a process view of affordances, rather than affordances being the end state [3]. We illustrate the process of becoming of the affordance of reachability on Facebook through multiple intra-actions among heterogeneous agents [2]. We follow Bloomfield et al. [3] in graduating from a dyadic notion of affordance, between a human agent and a material artifact [3], to a notion involving the co-presence of multiple actors [16]. However, the conceptualization of affordance discussed herein is distinct on two fronts. Firstly, the notion of co-presence espoused in extant literature (cf. [3], [16]) assumes the physical co-presence of different actors. For example, when socks afford easier wearing of boots, which afford attaching crampons, which afford walking on a snow-clad slope [16], the socks, boots, crampons, and snow-clad slopes have to be physically present in close proximity to allow the affordance of walkability on snow. In contrast, on Facebook, the marketers, individual users, Facebook's algorithms, Facebook's material features, and circulating posts and ads, are all dispersed in space and time. However, through certain configurations of the heterogeneous assemblage relationally constituted by the intra-actions among these actors, the physically absent gains presence [26]. This co-presence while at a distance [4] is achieved through the translation of the distant in the form of mobile artifacts [23], such as Page posts created by a firm or shared by its followers. Secondly, counter to the example of walkability on snow, the becoming of an affordance discussed here is not a simple cascade of affordances [16], one leading to another. Rather, in this case, agency flows in all directions [2]. Page followers and OMEGA get defined in terms of each other, through the actions of Facebook's algorithms which compute the relevance of OMEGA's content for its followers, in comparison with the content produced by OMEGA's competitors. Further, when OMEGA's followers share OMEGA's Page posts with their friends on Facebook, they alter the relational definition of OMEGA. The becoming of the affordance of reachability is, therefore, contingent upon the collective enactment of all these intra-actions.

ANT, which follows a relational and process-oriented ontology [24], allows us to foreground the intra-actions that constitutively define the relationality of an affordance, even when co-presence is from a distance [4]. Extant research that takes 
a process-based view of affordances is largely based on interpretive methods that do not allow exploring the relationships that performatively configure an affordance while co-presence is at a distance (see, for example, [3] for an ethnographic account, [14] for a multi-case account). On the contrary, ANT allows empirically following the establishment of point-to-point connections between actors through the traces left behind by agents moving through these connections [17]. These traces allow bringing back of distant people, places, and events [32] to a point where they can be absently present [22]. Furthermore, it suggests reality to be a relational effect such that it is produced and stabilized in interactions that are simultaneously material and social [39]. The strength of ANT to transcend the divide between the macrosocial and micro-social [24] allowed us to observe the multiple intra-actions among OMEGA's marketers, individual Facebook users, other firms, Facebook's algorithms and materiality, and circulating posts and ads, that contributed to the becoming of one particular social media affordance.

Through this paper we try to illustrate the usefulness of ANT as a method to study complex socio-material phenomena characterized by entities that cannot be pre-ordained as social or material, partaking in the becoming of the socio-material assemblage. Though we begin by imposing an ontological division between the "social" and "material", this boundary is imposed not for relegating to a bifurcated being ontology, but is imposed purely for analytical purposes. For example, despite these ontological boundaries, we trace how OMEGA's followers get relationally redefined when they start receiving its competitors' posts, and how the relational configuration of the affordance of reachability undergoes a change for OMEGA. This ontological openness implies that all qualities are emergent to the becoming of any particular being, and that assemblages are never complete "things", but are "processes of ongoing becoming in order to achieve certain accomplishments" [2] (p. 333).

In conclusion, this paper tries to go beyond the conceptualization of affordances actualized in the proximal co-presence of other agents (cf. [3]), by exploring a social media scenario where co-presence is from a distance. By using ANT, we trace the relationality that is implicit in the becoming of affordances [2] in such scenarios. We hope that this study will highlight the advantage of using ANT as a lens, over other interpretive approaches, for understanding complex technological scenarios involving diverse agents, often physically absent but notionally present [23].

\section{References}

1. Cecez-Kecmanovic, D., Galliers, R.D., Henfridsson, O., Newell, S., Vidgen, R.: The Sociomateriality of Information Systems: Current Status, Future Directions. MIS Q. 38, 809-830 (2014)

2. Introna, L.D.: Epilogue: Performativity and the Becoming of Sociomaterial Assemblages. In: Vaujany, F.-X. de, Mitev, N. (eds) Materiality and Space: Organizations, Artefacts and Practices, pp. 330-342. Palgrave Macmillan, Basingstoke (2013) 
3. Bloomfield, B.P., Latham, Y., Vurdubakis, T.: When Is an Affordance? Bodies, Technologies and Action Possibilities. Sociology. 44, 415-433 (2010)

4. Urry, J.: Connections. Environ. Plan. D Soc. Sp. 22, 27-37 (2004)

5. Kietzmann, J.H., Hermkens, K., McCarthy, I.P., Silvestre, B.S.: Social Media? Get Serious! Understanding the Functional Building Blocks of Social Media. Bus. Horiz. 54, 241-251 (2011)

6. Martini, A., Massa, S., Testa, S.: The Firm, the Platform and the Customer: A "Double Mangle" Interpretation of Social Media for Innovation. Inf. Organ. 23, 198-213 (2013)

7. Leonardi, P.M., Barley, S.R.: Materiality and Change: Challenges to Building Better Theory About Technology and Organizing. Inf. Organ. 18, 159-176 (2008)

8. Gibson, J.J.: The Theory of Affordances. In: The Ecological Approach to Visual Perception. Psychology Press, Hove and New York (1986)

9. Orlikowski, W.J., Barley, S.R.: Technology and Institutions: What Can Research on Information Technology and Research on Organizations Learn from Each Other? MIS Q. 25, 145-165 (2001)

10. Leonardi, P.M.: Materiality, Sociomateriality and Socio-Technical Systems: What Do These Terms Mean? How Are They Different? Do We Need Them? In: Leonardi, P.M., Nardi, B.A., Kallinilos, J. (eds) Materiality and Organizing: Social Interaction in a Technological World. pp. 25-45. Oxford University Press, Oxford (2012)

11. Leonardi, P.M.: Organizing Technology: Toward a Theory of Sociomaterial Imbrication. In: Academy of Management Proceedings. pp. 1-6. Academy of Management (2008)

12. Treem, J.W., Leonardi, P.M.: Social Media Use in Organizations: Exploring the Affordances of Visibility, Editability, Persistence, and Association. Commun. Yearb. 36, 143-189 (2012)

13. Majchrzak, A., Faraj, S., Kane, G.C., Azad, B.: The Contradictory Influence of Social Media Affordances on Online Communal Knowledge Sharing. J. Comput. Commun. 19, 38-55 (2013)

14. Cook, S., Brown, J.: Bridging Epistemologies: The Generative Dance Between Organizational Knowledge and Organizational Knowing. Organ. Sci. 10, 381-400 (1999)

15. Gaver, W.W.: Situating Action II: Affordances for Interaction: The Social Is Material for Design. Ecol. Psychol. 8, 111-129 (1996)

16. Michael, M.: These Boots Are Made for Walking...: Mundane Technology, the Body and Human-Environment Relations. J. Compos. Mater. 33, 928-940 (1999)

17. Latour, B.: Reassembling the Social: An Introduction to Actor-Network Theory. Oxford University Press, Oxford (2005)

18. Markus, M.L., Silver, M.S.: A Foundation for the Study of IT Effects: A New Look at DeSanctis and Poole's Concepts of Structural Features and Spirit. J. Assoc. Inf. Syst. 9, 609-632 (2008)

19. Leonardi, P.M.: When Flexible Routines Meet Flexible Technologies: Affordance, Constraint, and the Imbrication of Human and Material Agencies. MIS Q. 35, 147-167 (2011)

20. Hallerbach, I.P., Barrett, M., Faraj, S.: Emergence in Nascent Online Communities: An Affordance Perspective. In: Thirty Fourth International Conference on Information Systems. pp. 1-12 (2013)

21. Introna, L.D., Hayes, N.: On Sociomaterial Imbrications: What Plagiarism Detection Systems Reveal and Why It Matters. Inf. Organ. 21, 107-122 (2011)

22. Callon, M., Law, J.: Introduction: Absence-Presence, Circulation, and Encountering in Complex Space. Environ. Plan. D Soc. Sp. 22, 3-11 (2004)

23. Latour, B.: Visualisation and Cognition: Drawing Things Together. In: Kuklick, H. (ed.) Knowledge and Society Studies in the Sociology of Culture Past and Present. pp. 1-40. Jai Press, Stamford, CT (1986)

24. Law, J.: Notes on the Theory of the Actor-Network: Ordering, Strategy, and Heterogeneity. Syst. Pract. 5, 379-93 (1992)

25. Law, J.: On Power and its Tactics: A View from the Sociology of Science. Sociol. Rev. 34, 138 (1986) 
26. Licoppe, C.: “Connected” Presence: The Emergence of a New Repertoire for Managing Social Relationships in a Changing Communication Technoscape. Environ. Plan. D Soc. Sp. 22, 135156 (2004)

27. Walsham, G., Sahay, S.: GIS for District-Level Administration in India: Problems and Opportunities. MIS Q. 23, 39-65 (1999)

28. Latour, B.: Technology Is Society Made Durable. Sociol. Rev. 38, 103-131 (1990)

29. Callon, M., Latour, B.: Don't Throw the Baby Out with the Bath School! A Reply to Collins and Yearley. In: Pickering, A. (ed.) Science as Practice and Culture. pp. 343-368. The University of Chicago Press, Chicago and London (1992)

30. Collins, H.M., Yearley, S.: Epistemological Chicken. In: Science as Practice and Culture. pp. 301-326. The University of Chicago Press, Chicago and London (1992)

31. McLean, C., Hassard, J.: Symmetrical absence/symmetrical absurdity: Critical notes on the production of actor-network accounts. J. Manag. Stud. 41, 493-519 (2004)

32. Latour, B.: Science in action: How to follow scientists and engineers through society. Harvard University Press, Cambridge, Massachusetts (1987)

33. Orlikowski, W.J., Scott, S. V: The Algorithm and the Crowd: Considering the Materiality of Service Innovation. MIS Q. 39, 201-216 (2015)

34. Latour, B.: On Using ANT for Studying Information Systems: A (Somewhat) Socratic Dialogue. Soc. Study Inf. Commun. Technol. 62-76 (2004)

35. Miles, M.B., Huberman, A.M.: An Expanded Sourcebook: Qualitative Data Analysis. Sage, London (1994)

36. Akrich, M., Latour, B.: A Summary of a Convenient Vocabulary for the Semiotics of Human and Nonhuman Assemblies. In: Bijker, W.E., Law, J. (eds) Shaping Technology/ Building Society: Studies in Sociotechnical Change. pp. 259-264. MIT Press, Cambridge, MA (1992)

37. Introna, L.D.: The Enframing of Code Agency, Originality and the Plagiarist. Theory, Cult. Soc. 28, 113-141 (2011)

38. Latour, B.: Pandora's Hope: Essays on the Reality of Science Studies. Harvard University Press, Cambridge, MA and London (1999)

39. Law, J., Urry, J.: Enacting the Social. Econ. Soc. 33, 390-410 (2004)

40. EMarketer.com: Majority to Use Mobile Phones in India Next Year, www.emarketer.com/Article/Majority-Use-Mobile-Phones-India-Next-Year/1011780. (last accessed 29 September 2016)

41. Facebook.com: How News Feed Works, www.facebook.com/help/327131014036297/ (last accessed 13 May 2016)

42. Boland, B.: Organic Reach on Facebook: Your Questions Answered, www.facebook.com/business/news/Organic-Reach-on-Facebook. (last accessed 29 September 2016)

43. Manson, M.: Facebook Zero: Considering Life After the Demise of Organic Reach, https://social.ogilvy.com/facebook-zero-considering-life-after-the-demise-of-organic-reach/ (last accessed 29 September 2016)

44. Loomer, J.: No, Facebook Organic Page Reach Is Not Dead, www.jonloomer.com/2015/02/03/facebook-organic-page-reach-is-not-dead/ (2015) (last accessed 29 September 2016)

45. Facebook.com: Reach more people right from your Page, www.facebook.com/business/a/boost-a-post (last accessed 14 May 2016) 